\title{
Finite Element Analysis Simulations of Thermomechanical Head-Disk Interface Contact in Thermal Flying-Height Control Slider Design
}

\section{Jingan Song, Chang-Dong Yeo*}

Department of Mechanical Engineering, Texas Tech University

$7^{\text {th }}$ St \& Boston Ave, Lubbock, TX 79409 USA

*Corresponding author. Email: changdong.yeo@ttu.edu, tel: 806-834-5452, fax: 806-742-3540 


\begin{abstract}
In order to achieve higher recording density in hard disk drive (HDD), thermal flyingheight control (TFC) slider design has been used to reduce the physical spacing between the $\mathrm{read} / \mathrm{write}$ elements in the slider and the rotating disk surface. During the read/write operation in hard disk drives, the intermittent contact at the head-disk interface (HDI) directly affects its performance and reliability. In this study, the thermomechanical micro-contact between a TFC slider and a disk defect was systematically investigated through finite element analysis (FEA) modeling and simulations. The thermal actuation technology in a TFC slider was incorporated into the FEA model to enable the thermal protrusion of read/write sensors outward the air bearing surface (ABS). In order to obtain the scientific relationship between the thermal protrusion and the resulting HDI contact behavior, parametric FEA simulations were carried out based on the $2^{3}$-factorial design of experiment (DOE), where the surface temperature rise and the residual deformation on the TFC slider surface were used as the output parameters. From the statistical data analysis, it could be found that the larger thermal protrusion resulted in higher temperature rise and more residual deformation.
\end{abstract}

\title{
KEYWORDS
}

HDI Contact; Thermal Protrusion; Diamond-like Carbon 


\section{INTRODUCTION}

To achieve higher recording density in hard disk drive (HDD), it is required to reduce the physical spacing between the read/write elements in the slider and the rotating disk surface. Researchers have tried to apply the piezoelectric actuation technology into the slider design to control the active flying height [1-5]. However, its complicated fabrication process $[2,3]$ and the high operating temperature [6] prevented the mass production of the piezoelectric actuation slider. As an alternative solution, the thermal actuation technology was newly developed to control the head-media-spacing (HMS) adaptively [7], where a micro-heater in a slider manages the amount of thermal expansion of read/write elements outward the air bearing surface (ABS). A slider including this thermal actuation technology is typically called a thermal flying-height control (TFC) slider [8-11]. Compared to the piezoelectric actuation technology, it has simpler fabrication process with lower manufacturing cost, which enabled it to be successfully implemented into the actual HDD design.

Considering the active HMS of current HDD products is controlled to be a few nanometers through the thermal actuation technology, the head disk interface (HDI) can have intermittent micro-contacts during read/write operation. The high speed HDI contact gives rise to both mechanical stress and frictional heating on the contacting surfaces which can cause critical HDI failures. To further understand the mechanism of material degradation in relation to contact stress and temperature and thereby improve the slider design, researchers have investigated the thermomechanical contact behavior of solids using both computational and experimental methods. Chen and Wang developed a three-dimensional thermoelastoplastic sliding contact 
model for spherical bodies, from which they investigated the effects of sliding speed, heat partition, and thermal softening of materials on the contact behavior [12]. Coulibaly et al. developed an analytical model to study the thermomechanical coupling of rough surface high speed sliding contact of steel, and the model could well predict the average thermal response, heat flux distribution, temperature profile, and local shear stress field [13]. In addition, using an improved micro-contact model that takes account of substrate deformation and asperity interactions during surface contact $[14,15]$, Lee et al. have developed and proposed a novel thermomechanical contact model, which can provide the spatial distribution of in-situ stress and frictional temperature rise on the contacting bodies $[16,17]$. From the simulations results of HDI sliding contact, it was observed that the surface temperature rise by frictional heat generation was high enough to initiate the thermal degradation (graphitization or thermal softening) of head DLC film. Accordingly, once experiencing the thermal degradation by high speed surface contact, the degraded head DLC film could be easily worn out by the following surface contact. To verify the atomic structure change of head DLC film during HDI contact, micro-Raman measurement has been performed on the slider sample after HDD level test [18]. It was found that the burnishing wear area on the head DLC film clearly showed the increase of $\mathrm{sp}^{2}$-to-sp ${ }^{3}$ ratio and larger size of $\mathrm{sp}^{2}$ clusters, which indicates significant graphitization process on the head DLC film. Shi et al. investigated thermomechanical contacts between an elastic-plastic sphere and a rigid flat at different sliding speed, and it was found that both sliding friction coefficient and friction stress are significantly dependent on sliding speed while the maximum static friction coefficient is independent of sliding speed [19].

When HDI contact is investigated, finite element analysis (FEA) can also be a useful tool to estimate the in-situ stress and material deformation. In early stage of FEA research on 
thermomechanical HDI failures, for the convenient of analysis, normal contact without sliding was applied to analyze the plastic deformation on the coating and underlying magnetic layers [20]. Then, to obtain more realistic contact solutions, both normal and sliding motions were applied into the FEA modeling, which enabled to measure the surface flash temperature as well as mechanical stress and deformation [21, 22]. Recently, Song et al. have performed an advanced FEA modeling and simulation to examine the thermomechanical contact between disk asperity and TFC slider, where the material temperature rise, plastic strain, and scratch depth/width were measured at different flying height condition [23, 24]. In their FEA study, the TFC slider was modeled using the effective material properties based on the surface DLC coating and the underlying substrates, while the initial temperature was selectively applied depending on the substrate materials due to the thermal actuation technology [25]. All of these researches using simplified modeling of slider and asperity contact provided understanding in the contacts that occur at HDI, and helped improve the slider design. In spite of their outstanding modeling and simulation results, there would be some more technical points to improve the thermomechanical HDI analysis.

Based on the actual mechanism of thermal actuation technology in a slider, a microheater can provide considerable heat flux to the read/write elements and the other head substrate materials. The closer to the micro-heater would have the higher material temperature. Accordingly, the initial temperature of the material in a TFC slider needs to be given as a function of distance from the micro-heater. In addition, when the read/write elements area is thermally protruded outward the slider surface, it can generate film stress on the head DLC coating. Depending on the amount of the thermal protrusion and the coating thickness, such predetermined film stress could be critical to the HDI contact reliability. To get more physical 
insights into the thermomechanical HDI contact behavior, these two technical points were addressed in this paper. In the proposed FEA modeling, an effective heat flux was applied to the slider to generate the target thermal protrusion and the relevant DLC temperature. Using the three design factors (i.e., magnitude of thermal protrusion, sliding speed, and DLC thickness), parametric FEA simulation was performed based on the $2^{3}$-factorial DOE, where the surface temperature rise and the residual deformation of the slider surface were used as the output parameters.

\section{METHODS}

In this study, 3-dimensional FEA modeling and simulation has been performed using the explicit solver (Dynamic, Displacement-Temperature) in ABAQUS, which enables to investigate the thermomechanical surface damage of slider during HDI contact.

\subsection{Slider and Disk Defect: Materials and Geometrical Parameters}

Figure 1 depicts the slider and the disk defect used in the FEA model including their geometrical parameters. A simplified slider was used with the dimension of length $=2.5 \mu \mathrm{m}$, height $=2.5 \mu \mathrm{m}$, and thickness $=1 \mu \mathrm{m}$. As shown in Fig. 1(a), based on actual material design in $\mathrm{HDD}$, the slider was made of three different substrates (i.e., $\mathrm{AlTiC}, \mathrm{Al}_{2} \mathrm{O}_{3}$, and $\mathrm{NiFe}$ ), on which DLC overcoat was applied. It is noted that the length of each substrate material is not the same as actual slider, whose value was simply selected to examine the effects of substrate materials on the resulting contact performance of the slider. For the case of disk defect in Fig. 1(b), the hemi- 
spherical defect with the radius of $200 \mathrm{~nm}$ and the height of $13 \mathrm{~nm}$ was made of $\mathrm{Al}_{2} \mathrm{O}_{3}$, because it is known as one of the embedded defect materials in HDD [26]. This nanometer size particle was placed on top of the magnetic substrate made of $\mathrm{CoCrPt}$ which is the major magnetic material of disk. In FEA, to avoid the critical errors from boundary conditions, the height of the slider and disk substrate was much larger than the contact size. Table 1 shows the mechanical and thermal properties of materials used in this FEA model $[18,21]$. It is known that material properties are usually dependent on temperature. However, due to the unavailability of the temperature-dependent properties for the materials of head and disk, it was assumed that the material properties in this FEA simulation are constant for all temperatures.

\subsection{Mesh Design and Boundary Conditions}

Figure 2 shows the $z$-axis symmetrical FEA model for the slider and disk defect used in this study. As shown in Fig. 2(a), the four surfaces (top, front, back, and side) of the slider had the displacement constraints along $y$ and $z$ axes and the rotational constraints in all directions. And the four surfaces (bottom, front, back, and side) of the disk defect had the displacement constraints along $x$ and $z$ axes and the rotational constraints in all directions. To achieve cost effective simulation in terms of computation time while still obtaining accurate results in the contact region, bias mesh design was applied to the FEA model as shown in Fig. 2(b). The smaller and finer mesh was used near the contact area. The final FEA model was composed of 259,350 elements and 283,942 nodes, where the element type was C3D8RT to enable both displacement and temperature degrees of freedom. The initial temperature of the entire model before the heat flux was turned on and set to be $T=296 \mathrm{~K}$ (ambient room temperature). And the 
temperature boundary conditions were $T=296 \mathrm{~K}$ on the top, front, back, and side surfaces on the slider and the bottom, front, back, and side surfaces on the disk defect.

\subsection{Thermal Protrusion of Slider}

To simulate the thermal actuation technology in a slider design, a specific amount of heat flux was applied to the upper side of NiFe substrate (red box in Fig. 1(a)), which made the material protrusion outward the head surface (orange dashed line in Fig. 1(a)). In this study, the applying heat flux value was chosen to enable $1 \mathrm{~nm}-3 \mathrm{~nm}$ of surface protrusion with the predetermined temperature rise on the DLC surface, which was based on the technical discussion with the field HDD engineers. Considering the thermal protrusion technique can produce predetermined film stress as well as temperature rise on the head DLC overcoat, it can affect the material degradation process during HDI contact. This phenomenon is discussed more in the following section.

\subsection{Dynamic Contact}

In this FEA simulation, the sliding contact between the slider and the disk defect was conducted using a ramp profile of contact interference $(\delta)$ as shown in Fig. 3, where the coefficient of friction (COF) was 0.1 [27]. The slider was moved horizontally with the velocity of $V_{x}$, while the disk defect was moved vertically with the velocity of $V_{y}$. The contact interference changed from 0 at the leading edge of the slider (AlTiC substrate zone) to $3 \mathrm{~nm}$ at the trailing edge $\left(\mathrm{Al}_{2} \mathrm{O}_{3}\right.$ substrate zone). It is noted that the $\delta$ value in Fig. 3 was based on the 
slider surface without the thermal protrusion. Therefore, the actual $\delta$ value in FEA simulations is proportional to the magnitude of the applied thermal protrusion.

\section{$2.52^{3}$-Factorial Design of Experiment (DOE)}

When a TFC slider makes a high speed contact with a disk defect, its physical damage or failure can be affected by several design factors. In addition, the mechanism of material degradation by dynamic surface contact is complicatedly related to the resulting contact stress and temperature rise by frictional heat generation. In this paper, to systematically evaluate the effects of contact related design factors on the resulting stress and temperature rise, $2^{3}$-factorial DOE analysis was performed. Based on the authors' previous research [16], there are three main factors, which can critically affect the thermomechanical HDI contact performance, i.e., the sliding velocity $\left(V_{x}\right)$, the magnitude of thermal protrusion $\left(h_{t}\right)$, and the thickness of head DLC overcoat $(t)$. It is noted that i) the sliding speed is directly related to the temperature rise by frictional heat generation, ii) the thermal protrusion produces the pre-determined film stress and the pre-determined temperature rise on head materials, and iii) the DLC thickness affects the wear resistance during HDI contact. Table 2 shows the two level values for the three main factors, which were referring to recent HDD designs. Then, the design matrix for $2^{3}$-factorial DOE was constructed as shown in Table 3. Accordingly, in this study, total 8 FEA simulations have been performed. For the systematic analysis of the thermomechanical surface degradation during HDI contact, the surface temperature rise $\left(T_{\mathrm{s}}\right)$ and the surface residual deformation $\left(\delta_{\mathrm{r}}\right)$ of the slider were used as the output parameters. Therefore, from the statistical data analysis, we 
could obtain the main and coupled effects of the three design factors on the resulting surface deformation and surface temperature rise.

\section{RESULTS}

\subsection{Pre-Determined Film Stress and Temperature on Head DLC due to Thermal} Protrusion

As described in Sec. 2.1, the thermal protrusion technique in a slider produces predetermined film stress $\left(\sigma_{\text {pre }}\right)$ and temperature $\left(T_{\text {pre }}\right)$ on the head DLC overcoat, which can affect the in-situ material degradation process during HDI contact. In this FEA study, the heat flux was applied to the NiFe substrate as shown in Fig. 1(a), and the pre-determined temperature and predetermined film stress values were measured at the surface of head DLC overcoat on the $\mathrm{NiFe}$ substrate region, whose results were summarized in Fig. 4. Examining the measured $\sigma_{\text {pre }}$ and $T_{\text {pre }}$ values with respect to the two main factors (i.e., $h_{t}$ and $t$ ), it could be observed that $\sigma_{\text {pre }}$ and $T_{\text {pre }}$ were not much affected by the applied DLC thickness $(t)$, but their values were highly dependent on the magnitude of protrusion $\left(h_{t}\right)$. For example, when the heat flux increased to make the thermal protrusion of $3 \mathrm{~nm}$, the temperature of head DLC changed from $296 \mathrm{~K}$ to $400 \mathrm{~K}$ and its film stress increased to $1.2 \mathrm{GPa}$. Considering the mechanism of material degradation by temperature and stress (i.e., thermal softening process that lowers the yield strength of materials), it could be implying that a slider with higher thermal protrusion could be more susceptible to HDI contact. 


\subsection{Surface Residual Deformation (or Scratch Depth) $\left(\delta_{\mathbf{r}}\right)$}

During the high speed sliding contact with the disk defect, the slider could experience permanent surface damage due to local high stress. It is noted that in real HDD operation the surface damage by HDI contact would be attributed to both plastic deformation and wear of materials. However, in this study, due to the unavailability of damage evolution parameters for DLC and underlying substrate materials, the wear behavior (or element removal process) could not be implemented in the FEA model. Accordingly, the residual deformation or scratch depth from the simulation result was obtained by the material plastic deformation only.

Figure 5 shows the surface profile of a damaged slider obtained from the simulation results of Test 1 , whose test conditions can be found in Table 3 . The $x$-axis is the distance from the leading edge of the slider as seen in Fig. 1(a), while the $y$-axis is the corresponding residual head deformation. It could be observed that the magnitude of head surface damage was highly dependent on the substrate materials. Examining the residual deformation of head surface in Fig. 5, the $\mathrm{NiFe}$ region showed the scratch depth up to $\sim 1 \mathrm{~nm}$, while the $\mathrm{AlTiC}$ and $\mathrm{Al}_{2} \mathrm{O}_{3}$ regions showed limited damage with the scratch depth less than $0.1 \mathrm{~nm}$. Under the same contact load condition where the applied stress is greater than the yield strength of materials, the softer materials develop more plastic deformation than the harder and stiffer materials. Referring to Table 1, the material strength (Young's modulus and yield strength) of NiFe is much lower than those of $\mathrm{AlTiC}$ and $\mathrm{Al}_{2} \mathrm{O}_{3}$. Accordingly, the NiFe substrate region could develop more surface damage than the $\mathrm{AlTiC}$ and $\mathrm{Al}_{2} \mathrm{O}_{3}$ substrate regions. In addition, comparing the yield strengths of DLC and substrate materials, it is found that DLC is much stronger than NiFe but close to AlTiC and $\mathrm{Al}_{2} \mathrm{O}_{3}$. Therefore, the large surface residual deformation in the $\mathrm{NiFe}$ substrate region is dominantly attributed to the deformation of softer NiFe, whereas the surface residual 
deformation in the $\mathrm{AlTiC}$ and $\mathrm{Al}_{2} \mathrm{O}_{3}$ substrate regions is almost equally attributed to the deformations of DLC and substrate materials, which was confirmed by obtaining the displacement of the nodes at the interface of DLC and substrate materials.

As described in Sec. 2.5, total 8 FEA simulations have been performed to investigate the effects of three main factors (i.e., the sliding velocity $\left(V_{x}\right)$, the magnitude of thermal protrusion $\left(h_{t}\right)$, and the head DLC thickness $\left.(t)\right)$ on the residual head deformation. For the $2^{3}$-factorial DOE analysis, the residual head deformation measured at the mid-point of head DLC on the NiFe substrate region (i.e., the position at $x=1,900 \mathrm{~nm}$ in Fig. 5) was used as the output parameter, which are summarized in Table 3. Figure 6 shows the individual contribution of the three main factors to the resulting head deformation. First, from the Figs. 6(a) and (b), it was observed that the residual head deformation was not significantly affected by the sliding velocity $\left(V_{x}\right)$ and the head DLC thickness $(t)$, even though the faster contact speed and the thinner head DLC showed slightly higher head deformation. However, it should be noted that all the FEA simulations in this study were based on single time HDI sliding contact. If repeated sliding contact is applied, it would be possible that these two main factors could be more correlated to the surface damage process, because the sliding velocity increases the frictional temperature rise on the head DLC which can cause its thermal degradation (i.e., thermal softening process or graphitization). In other words, under the repeated contact condition, the higher sliding speed and thinner DLC can make more surface damage thus leading to better correlation in between.

Next, examining the Fig. 7(c), it could be found that the residual head deformation was highly dependent on the magnitude of thermal protrusion $\left(h_{\mathrm{t}}\right)$. The more thermal protrusion caused the higher scratch depth, which could be explained by the in-situ HDI contact behavior and the pre-determined film stress on the head DLC overcoat. Figure 8 shows the comparison of 
in-situ contact stress of the slider at the thermal protrusion of $h_{\mathrm{t}}=1 \mathrm{~nm}$ (Fig. 7(a)) and $h_{\mathrm{t}}=3 \mathrm{~nm}$ (Fig. 7(b)). As described in Sec. 2.1, the more thermal protrusion not only produces higher film stress on the head DLC but it enables larger contact interference during HDI contact. Therefore, the higher stress developed at $h_{\mathrm{t}}=3 \mathrm{~nm}$ could cause wider and deeper scratch on the surface than the simulation at $h_{\mathrm{t}}=1 \mathrm{~nm}$.

\subsection{Surface Temperature Rise $\left(T_{s}\right)$}

The temperature rise by frictional heat generation is directly related to the thermal degradation of contacting materials. It is known that the mechanical strength of DLC coating and magnetic materials become lower at higher temperature [28], which accordingly can exacerbate their damage process at the following contact. In similar with Sec. $3.2,2^{3}$-factorial DOE analysis has been performed to investigate the effects of the three main factors on the surface temperature rise. The in-situ temperature value measured at the same position as the residual head deformation in Sec. 3.2 was used as the output parameter, which was summarized in Table 3. Figure 8 shows the individual contribution of the three main factors to the resulting surface temperature rise. It could be observed that the surface temperature of head DLC was increased with the sliding velocity $\left(V_{x}\right)$, the thermal protrusion $\left(h_{t}\right)$, and the DLC thickness $(t)$. First, the dependence of head temperature on the sliding velocity and the thermal protrusion (Figs. 8(a) and (c)) could be described by the mechanism of frictional heat generation during HDI sliding contact. It is known that the frictional heat flux $(q)$ during sliding contact is proportional to the sliding velocity $\left(V_{x}\right)$ and contact pressure $(p)$ like $q=p V_{x}$ (: friction coefficient). In this FEA simulation, the more thermal protrusion $\left(h_{t}\right)$ can make higher contact pressure due to the larger 
contact interference. Therefore, it could be very reasonable that the head DLC temperature showed the increasing trend with $V_{x}$ and $h_{t}$ in Figs. 8(a) and (c). Next, for the relationship between DLC thickness and surface temperature rise, it could be explained by the contact stress of multi-layered system. When a stiffer DLC film is applied onto softer substrate, the thicker DLC produces higher contact stress than the thinner DLC [17]. Accordingly, in this FEA study, the slider with the thicker DLC film could develop higher contact stress, which could lead to higher frictional heat flux and temperature rise during the sliding contact. It is also noted that the surface temperature rise $\left(T_{s}\right)$ is made of two terms, i.e., the pre-determined temperature rise by thermal protrusion $\Delta T_{\text {pre }}$ and the frictional temperature rise $\Delta T_{\text {friction. }}$. Comparing the contribution of $\Delta T_{\text {pre }}$ and $\Delta T_{\text {friction }}$ to $T_{s}$ in Table 3 , it could be observed that under the low thermal protrusion condition $\left(h_{t}=1 \mathrm{~nm}\right)$ the surface temperature rise was more likely affected by the frictional heat, which was more obvious at high speed condition. For the case of high thermal protrusion $\left(h_{t}=3\right.$ $\mathrm{nm})$, the pre-determined temperature rise ( $\left.\Delta T_{\text {pre }}\right)$ was more dominant on the surface temperature rise.

\section{CONCLUSIONS}

The thermomechanical contact between slider and disk defect was systematically investigated through parametric FEA simulations, where the thermal protrusion technique was implemented in the slider design. Based on $2^{3}$-full factorial design, total 8 FEA simulations were performed to examine the scientific relationship between the three main factors (i.e., sliding velocity, head DLC thickness, and the magnitude of thermal protrusion) and the two output parameters (i.e., residual deformation and frictional temperature rise). First, it was observed that 
the head DLC overcoat developed considerable pre-determined film stress and temperature rise before actual surface contact due to the thermal protrusion. The pre-determined film stress and temperature increased with the magnitude of thermal protrusion, but they were not much affected by the head DLC thickness. Second, after the single time HDI sliding contact, the residual deformation of slider surface was proportional to the magnitude of thermal protrusion, but it did not show significant dependency on the sliding velocity and head DLC thickness. Lastly, it was observed that the frictional temperature rise showed the increasing trend with all three main factors. Therefore, from the results of this parametric FEA study, it could be concluded that the larger thermal protrusion and the faster HDI contact speed can result in critical thermomechanical damage on head DLC overcoat.

\section{ACKNOWLEDGMENT}

This research was supported by grants from the National Science Foundation under Grant number NSF-CMMI 1463078 and Seagate Technology. The authors gratefully acknowledge these supports. 


\section{REFERENCES}

[1] Yeack-Scranton, C. E., Khanna, V. D., Etzold, K. F., and Praino, A. P. (1990), “An Active Slider for Practical Contact Recording," IEEE Trans. Magn., 26(5), pp 2478-2483. DOI: $10.1109 / 20.104770$

[2] Kurita, M., Yamazaki, T., Kohira, H., et al. (2002), "An Active-Head Slider with a Piezoelectric Actuator for Controlling Flying Height," IEEE Trans. Magn., 38(5), pp 2102-2104. DOI: 10.1109/TMAG.2002.802843

[3] Kurita, M., Tsuchiyama, R., Tokuyama, M., et al. (2003), "Flying-Height Adjustment of a Magnetic Head Slider with a Piezoelectric Micro-Actuator," IEEE Trans. Magn., 39(5), pp 2480-2482. DOI: 10.1109/TMAG.2003.816444

[4] Tagawa, N., Kitamura, K., and Mori, A. (2003), "Design and Fabrication of Mems-Based Active Slider Using Double-Layered Composite PZT Thin Film in Hard Disk Drives," IEEE Trans. Magn., 39(2), pp 926-931. DOI: 10.1109/TMAG.2003.808950

[5] Juang, J. -Y., Bogy, D. B., and Bhatia, C. S. (2007), "Design and Dynamics of Flying Height Control Slider with Piezoelectric Nanoactuator in Hard Disk Drives," J. Tribol., 129(1), pp 161-170. DOI: 10.1115/1.2401208

[6] Suzuki, K., and Kurita, M. (2004), "A MEMS-Based Active-Head Slider for Flying Height Control in Magnetic Recording,” JSME Int. J. Ser. B, 47(3), pp 453-458. DOI: 10.1299/jsmeb.47.453

[7] Mächtle, P., Berger, R., Dietzel, A., et al. (2001), "Integrated Microheaters for In-Situ Flying-Height Control of Sliders Used in Hard-Disk Drives," 14th IEEE International Conference on Micro Electro Mechanical Systems, Interlaken, Switzerland, 2001.

[8] Kurita, M., Tokuyama, M., Nakamoto, K., et al. (2005), "Flying-Height Reduction of Magnetic-Head Slider Due to Thermal Protrusion," IEEE Trans. Magn., 41(10), pp 30073009. DOI: 10.1109/TMAG.2005.855240

[9] Kurita, M., Shiramatsu, T., Miyake, K., et al. (2006), "Active Flying-Height Control Slider Using MEMS Thermal Actuator," Microsyst. Technol., 12(4), pp 369-375. DOI: $10.1007 / \mathrm{s} 00542-006-0104-4$

[10] Zheng, H., Li, H., and Talke, F. E. (2009), "Numerical Simulation of a Thermal Flying Height Control Slider with Dual Heater and Insulator Elements," IEEE Trans. Magn., 45(10), pp 3628-3631. DOI: 10.1109/TMAG.2009.2024890 
[11] Liu, J., Li, J., Xu, J., and Yoshida, S. (2010), "Optimization of Micro-Thermal Actuator for Flying Height Control,” Microsyst. Technol., 16(1-2), pp 249-255. DOI:

$10.1007 / \mathrm{s} 00542-009-0852-\mathrm{z}$

[12] Chen, W. W., and Wang, Q. J. (2008), "Thermomechanical Analysis of Elastoplastic Bodies in a Sliding Spherical Contact and the Effects of Sliding Speed, Heat Partition, and Thermal Softening," J. Tribol., 130, pp 041402.

[13] Coulibaly, M., Chassaing, G., and Philippon, S. (2014), "Thermomechanical coupling of rough contact asperities sliding at very high velocity,” Tribol. Int., 77, pp 86-96.

[14] Yeo, C. -D., Katta, R. R., and Polycarpou, A. A. (2009), "Improved Elastic Contact Model Accounting for Asperity and Bulk Substrate Deformation,” Tribol. Lett., 35, pp 191-203. DOI: 10.1007/s11249-009-9448-0

[15] Yeo, C. -D., Katta, R. R., Lee, J., and Polycarpou, A. A. (2010), 'Effect of Asperity Interactions on Rough Surface Elastic Contact Behavior: Hard Film on Soft Substrate," Tribol. Int., 43, pp 1438-1448. DOI: 10.1016/j.triboint.2010.01.021

[16] Lee, S., and Yeo, C. -D. (2012), "Microwear Mechanism of Head Carbon Film During Head Disk Interface Sliding Contact,” Tribol. Int., 45, pp 30-37. DOI:

10.1016/j.triboint.2011.09.007

[17] Lee, S., Yeo, C. -D, Purani, D., and Kim, A. S. (2014), "Thermomechanical Contact Between Magnetic Recording Head and Disk Defect Accounting for Heat Partition Factor,” IEEE Trans. Magn., 50, pp 119-125. DOI: 10.1109/TMAG.2013.2285351

[18] Lee, S., He, M., and Yeo, C.-D. (2014), "Thermal Degradation and Burnishing Wear of Thin Carbon Film by Frictional Heat Generation,” J. Tribol., 136, pp 041603. DOI: $10.1115 / 1.4027749$

[19] Shi, X., Wu, A., Jin, C., and Qu, S. (2015) "Thermomechanical modeling and transient analysis of sliding contacts between an elastic-plastic asperity and a rigid isothermal flat," Tribol. Int., 81, pp 53-60.

[20] Komvopoulos, K. (2000), “Head-Disk Interface Contact Mechanics for Ultrahigh Density Magnetic Recording," Wear, 238, pp 1-11.

[21] Yu, N., Polycarpou, A. A., and Hanchi, J. V. (2010), “Thermomechanical Finite Element Analysis of Slider-Disk Impact in Magnetic Storage Thin Film Disks," Tribol. Int., 43, pp 737-745. DOI: 10.1016/j.triboint.2009.10.014

[22] Ovcharenko, A., Yang, M., Chun, K., and Talke, F. E. (2011), “Transient Thermomechanical Contact of an Impacting Sphere on a Moving Flat,” J. Tribol., 133, pp 031404. DOI: $10.1115 / 1.4003996$

[23] Song, W., Ovcharenko, A., Knigge, B., et al. (2012), "Effect of Contact Conditions During Thermo-Mechanical Contact Between a Thermal Flying Height Control Slider and a Disk Asperity," Tribol Int, 55, pp 100-107. DOI: 10.1016/j.triboint.2012.05.016 
[24] Song, W., Ovcharenko, A., Yang, M., et al. (2012), "Contact Between a Thermal Flying Height Control Slider and a Disk Asperity," Microsyst. Technol., 18, pp 1549-1557. DOI: $10.1007 / \mathrm{s} 00542-012-1591-0$

[25] Li, H., Zheng, H., Fritzsche, J., et al. (2010), "Simulation of Flying Height and Response Time of Thermal Flying Height Control Sliders with Thermal Insulators," IEEE Trans. Magn., 46, pp 1292-1294.

[26] Sharma, V., Kim, S. -H., and Choa, S. -H. (2001), "Head and Media Design Considerations for Reducing Thermal Asperity," Tribol. Int., 34, pp 307-314. DOI: 10.1016/S0301-679X(00)00142-0

[27] Voevodina, A. A., Phelpsb, A. W., Zabinskia, J. S., and Donley, M. S., (1996), "Friction Induced Phase Transformation of Pulsed Laser Deposited Diamond-Like Carbon," Diamond and Related Materials, 5(11), pp 1264-1269. DOI:10.1016/09259635(96)00538-9

[28] Miyoshi, K. "Structures and Mechanical Properties of Natural and Synthetic Diamonds," https://archive.org/details/nasa_techdoc_19980210770 (accessed August 19, 2015) 


\section{Table Caption List}

Table 1 Mechanical and thermal material properties

Table 2 Two level values of the three main factors

Table 3 Design matrix for $2^{3}$-full factorial DOE including the three main factors $\left(V, h_{t}, t\right)$ and the two output parameters $\left(T_{s}, \delta_{\mathrm{r}}\right)$ 


\section{Figure Captions List}

Fig. 1 Schematic of the slider and disk defect used in FEA modeling and simulation, a) Slider with three different substrates and DLC overcoat, b) Spherical disk defect placed on magnetic materials

Fig. 2 Symmetrical FEA model of the slider and disk defect: a) The structure of the model and b) The mesh design

Fig. 3 Dynamic contact profile between slider and disk defect

Fig. 4 Pre-determined temperature $\left(T_{p r e}\right)$ and pre-determined stress $\left(\sigma_{p r e}\right)$ values on the head DLC overcoat caused by thermal protrusion technique

Fig. 5 Residual deformation of the slider surface obtained from Test $1\left(V_{x}=25\right.$ $\left.\mathrm{m} / \mathrm{s}, h_{t}=1 \mathrm{~nm}, t=1.5 \mathrm{~nm}\right)$

Fig. 6 Residual deformation of slider in regards to the three main factors; a) $\delta_{\mathrm{r}}$ vs. $V_{x}$, b) $\delta_{\mathrm{r}}$ vs. $t$, and c) $\delta_{\mathrm{r}}$ vs. $h_{t}$

Fig. 7 In-situ stress on the DLC overcoat of the slider (bottom view) of a) test 1 $\left(V_{x}=25 \mathrm{~m} / \mathrm{s}, h_{t}=1 \mathrm{~nm}, t=1.5 \mathrm{~nm}\right)$ and b) test $3\left(V_{x}=25 \mathrm{~m} / \mathrm{s}, h_{t}=3 \mathrm{~nm}, t\right.$ $=1.5 \mathrm{~nm}$ ), where 1 is the $\mathrm{AlTiC}$ substrate region, 2 and 4 are the $\mathrm{Al}_{2} \mathrm{O}_{3}$ substrate regions, and 3 is the $\mathrm{NiFe}$ substrate region.

Fig. 8 Surface temperature rise $\left(T_{S}\right)$ of slider in regards to the three main factors; a) $T_{s}$ vs. $V_{x}$, b) $T_{s}$ vs. $t$, and c) $T_{s}$ vs. $h_{t}$ 
Table 1 Mechanical and thermal material properties

\begin{tabular}{cccccc}
\hline & $\mathrm{NiFe}$ & $\mathrm{DLC}$ & $\mathrm{AlTiC}$ & $\mathrm{Al}_{2} \mathrm{O}_{3}$ & $\mathrm{CoCrPt}$ \\
Density $\left(\mathrm{kg} / \mathrm{m}^{3}\right)$ & 8120 & 2150 & 4250 & 3970 & 8900 \\
Young's modulus $(\mathrm{GPa})$ & 110 & 168 & 410 & 380 & 130 \\
Poisson's ratio & 0.3 & 0.3 & 0.3 & 0.25 & 0.3 \\
Yield stress $(\mathrm{GPa})$ & 1.7 & 5 & 6.86 & 5.5 & 2.67 \\
Conductivity $(\mathrm{W} / \mathrm{mK})$ & 15 & 0.52 & 20 & 1.5 & 6.03 \\
& & & & & 411 \\
Specific heat $(\mathrm{J} / \mathrm{kgK})$ & 500 & 500 & 200 & 775 & 12.5 \\
\hline Thermal expansion $\left(10^{-6} / \mathrm{K}\right)$ & 12 & 6.95 & 5 & 5.5 & \\
\hline
\end{tabular}


Table 2 Two level values of the three main factors

\begin{tabular}{cccc}
\hline & $V_{x}(\mathrm{~m} / \mathrm{s})$ & $h_{t}(\mathrm{~nm})$ & $t(\mathrm{~nm})$ \\
\hline High level $(+1)$ & 50 & 3 & 3 \\
Low level (-1) & 25 & 1 & 1.5 \\
\hline
\end{tabular}


Table 3 Design matrix for $2^{3}$-full factorial DOE including the three main factors $\left(V, h_{t}, t\right)$ and the two output parameters $\left(T_{s}, \delta_{\mathrm{r}}\right)$

\begin{tabular}{|c|c|c|c|c|c|c|c|}
\hline \multirow{2}{*}{ Test } & \multirow{2}{*}{$V_{x}(\mathrm{~m} / \mathrm{s})$} & \multirow{2}{*}{$h_{t}(\mathrm{~nm})$} & \multirow{2}{*}{$t(\mathrm{~nm})$} & \multicolumn{3}{|c|}{ Temperature Rise $(\mathrm{K})$} & \multirow{2}{*}{$\delta_{\mathrm{r}}(\mathrm{nm})$} \\
\hline & & & & $\Delta T_{\text {pre }}$ & $\Delta T_{\text {friction }}$ & $T_{S}$ & \\
\hline 1 & $(-1) 25$ & $(-1) 1$ & $(-1) 1.5$ & 31 & 24 & 351.0 & 0.94 \\
\hline 2 & $(+1) 50$ & $(-1) 1$ & $(-1) 1.5$ & 31 & 44.6 & 371.6 & 0.91 \\
\hline 3 & $(-1) 25$ & $(+1) 3$ & $(-1) 1.5$ & 103 & 25.9 & 424.9 & 1.87 \\
\hline 4 & $(+1) 50$ & $(+1) 3$ & $(-1) 1.5$ & 103 & 52.7 & 451.7 & 1.86 \\
\hline 5 & $(-1) 25$ & $(-1) 1$ & $(+1) 3$ & 31 & 37.2 & 364.2 & 0.94 \\
\hline 6 & $(+1) 50$ & $(-1) 1$ & $(+1) 3$ & 31 & 74.2 & 401.2 & 0.92 \\
\hline 7 & $(-1) 25$ & $(+1) 3$ & $(+1) 3$ & 103 & 41 & 440.0 & 1.88 \\
\hline 8 & $(+1) 50$ & $(+1) 3$ & $(+1) 3$ & 103 & 80.3 & 479.3 & 1.82 \\
\hline
\end{tabular}


(a)

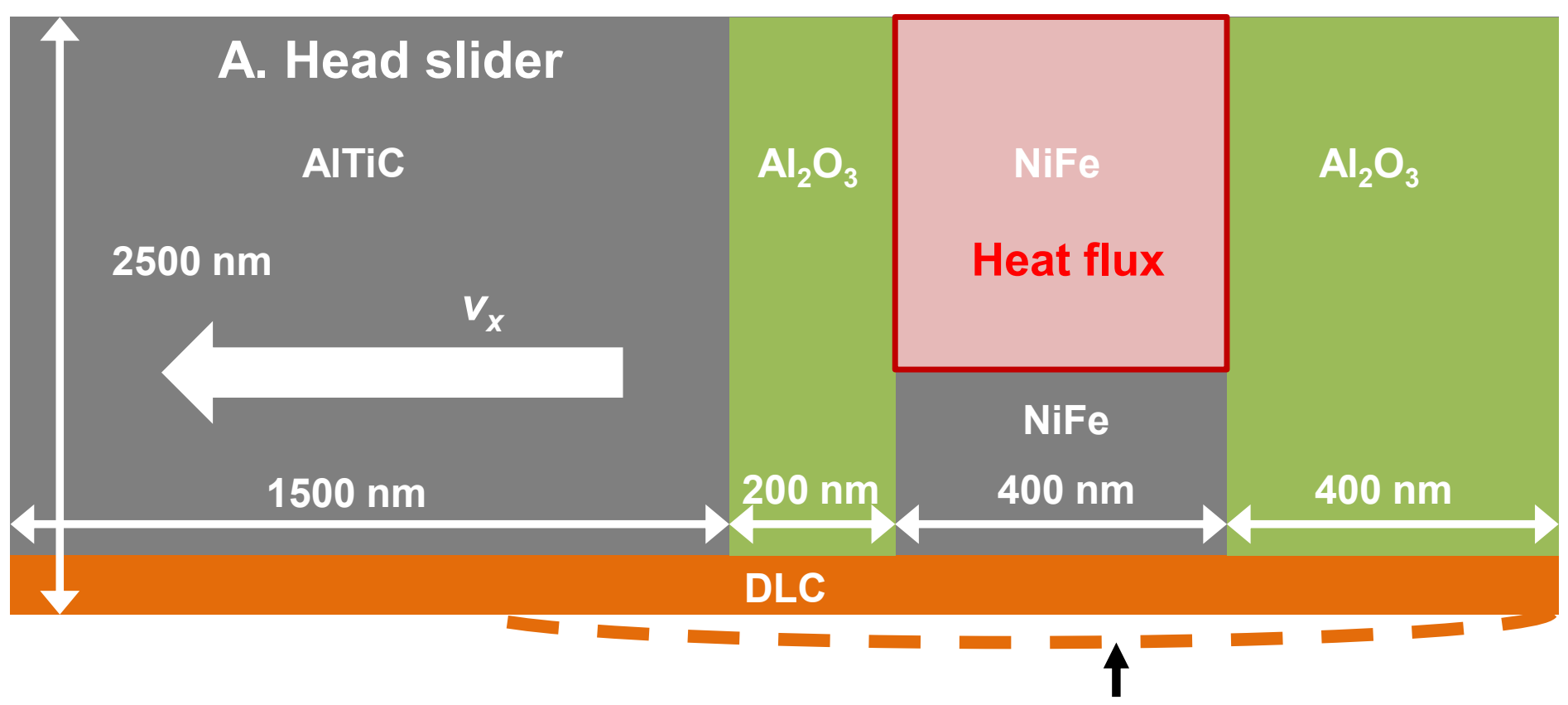

Thermal protrusion

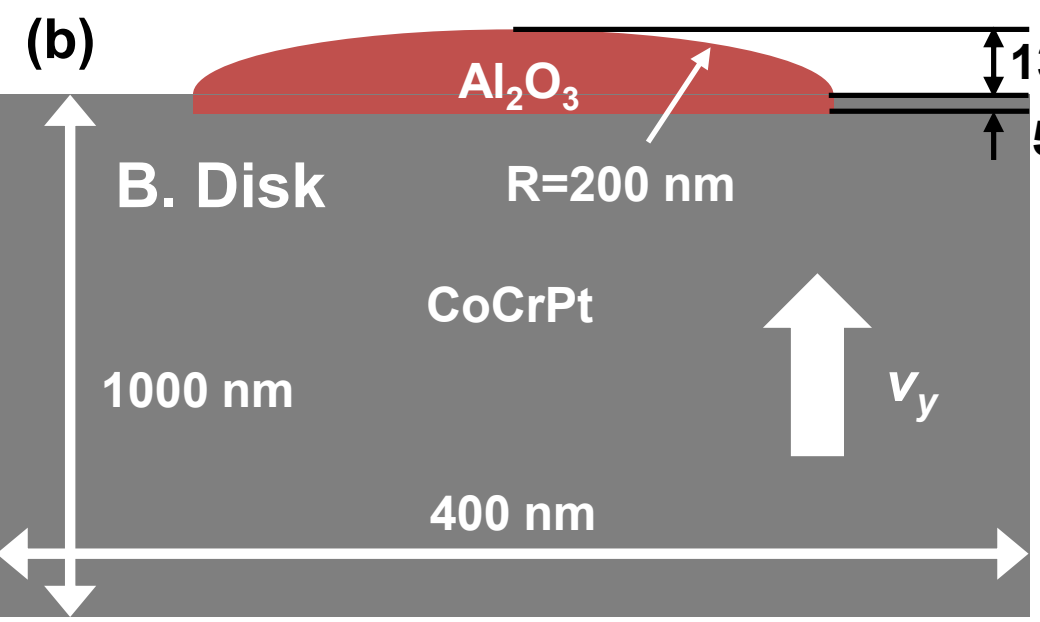

Fig. 1 Schematic of the slider and disk defect used in FEA modeling and simulation, a) Slider with three different substrates and DLC overcoat, b) Spherical disk defect placed on magnetic materials 


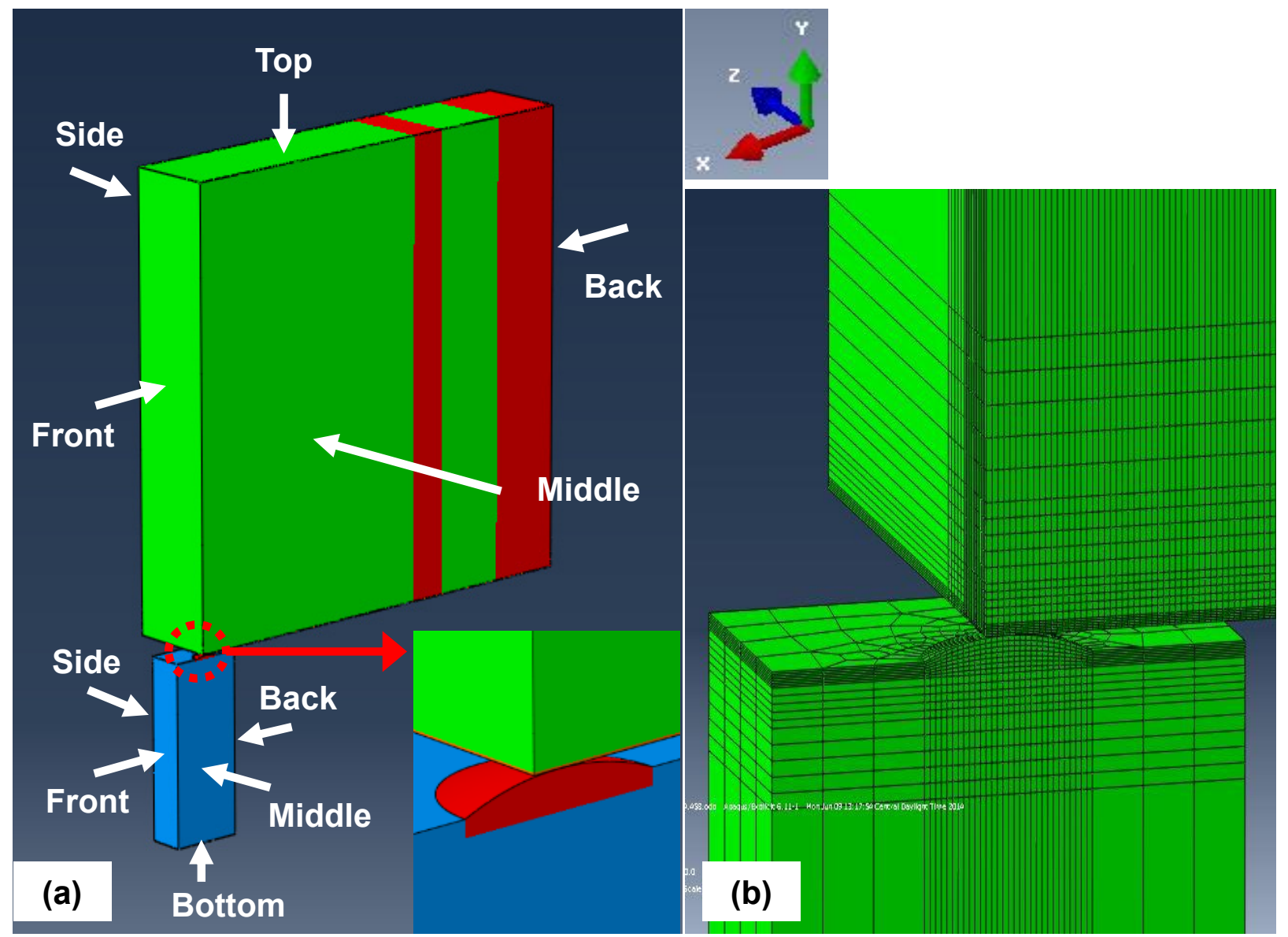

Fig. 2 Symmetrical FEA model of the slider and disk defect: (a) The structure of the model and (b) the mesh design 


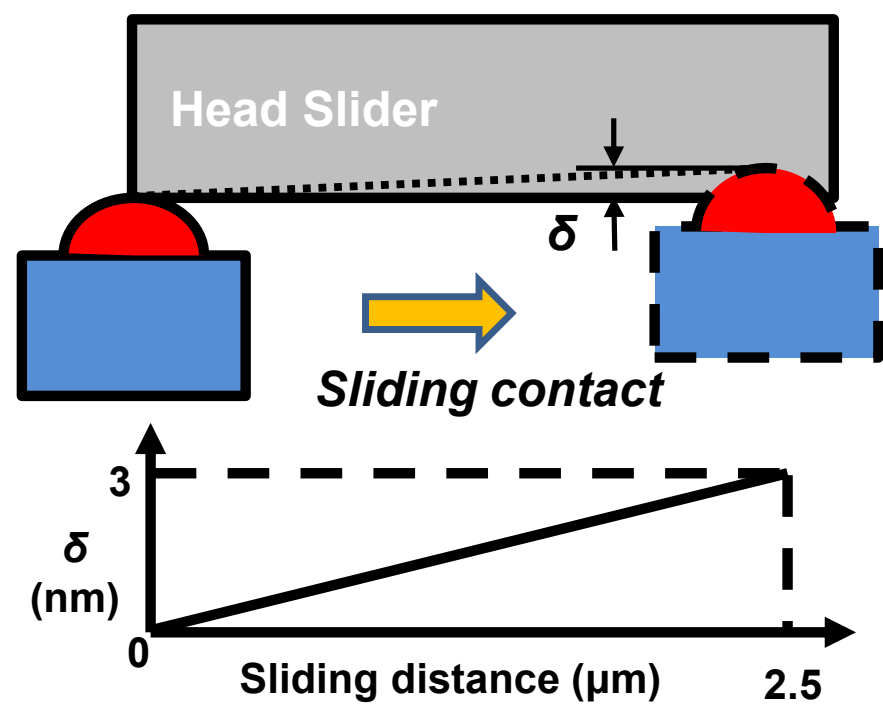

Fig. 3 Dynamic contact profile between slider and disk defect 


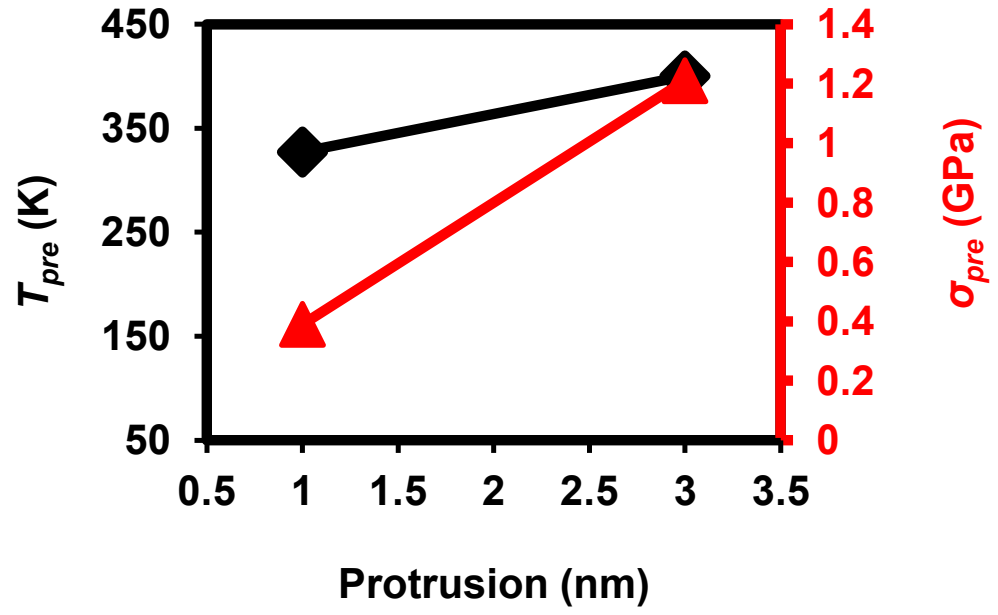

Fig. 4 Pre-determined temperature $\left(T_{\text {pre }}\right)$ and pre-determined stress $\left(\sigma_{\text {pre }}\right)$ values on the head DLC overcoat caused by thermal protrusion technique 


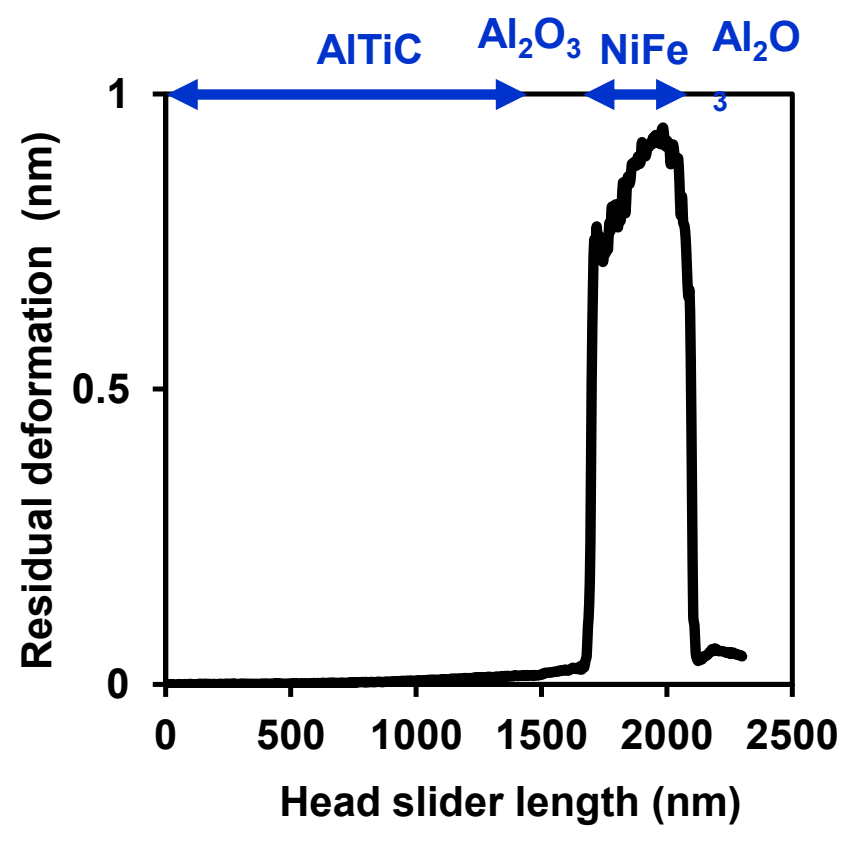

Fig. 5 Residual deformation of the slider surface obtained from Test 1 $\left(V_{x}=25 \mathrm{~m} / \mathrm{s}, h_{t}=1 \mathrm{~nm}, t=1.5 \mathrm{~nm}\right)$ 

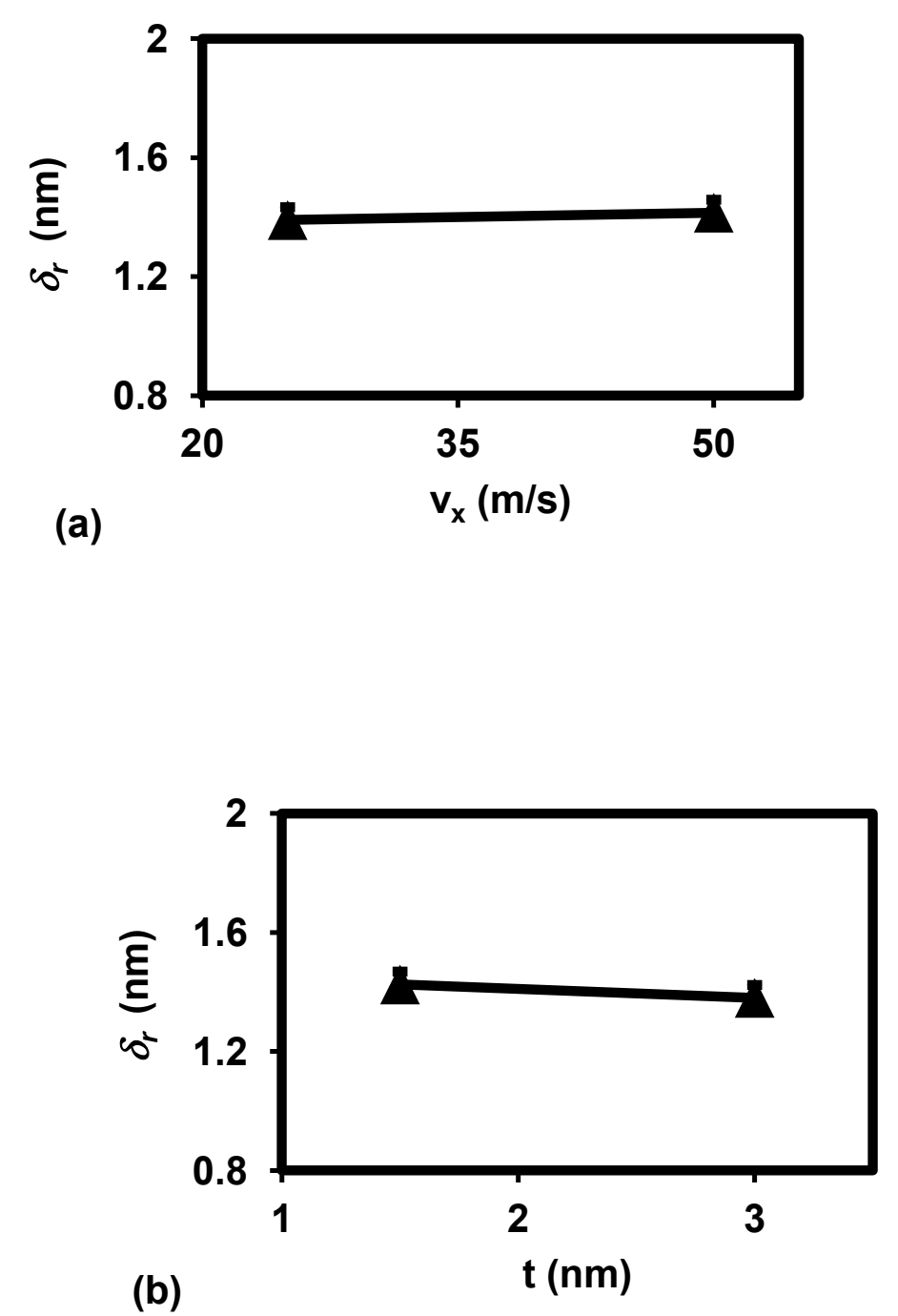

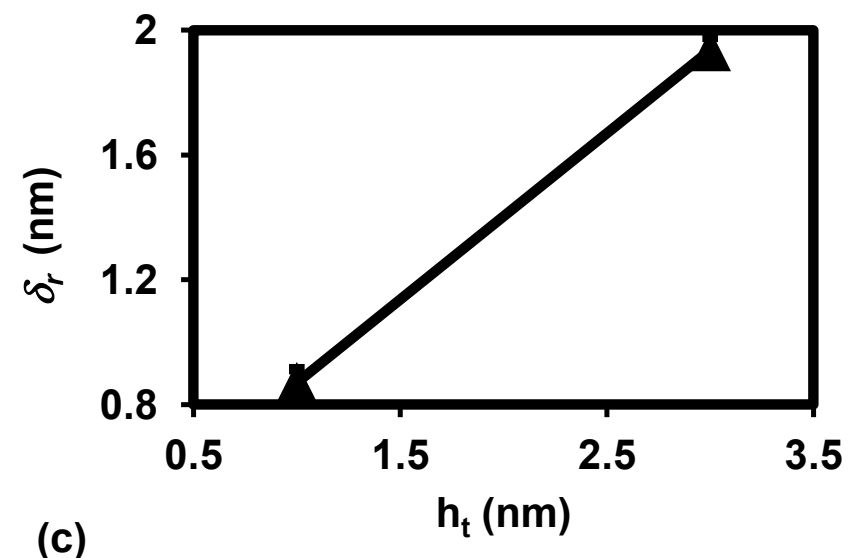

Fig. 6 Residual deformation of slider in regards to the three main factors; a) $\delta_{\mathrm{r}}$ vs. $V_{x}$, b) $\delta_{\mathrm{r}}$ vs. $t$, and c) $\delta_{\mathrm{r}}$ vs. $h_{t}$ 


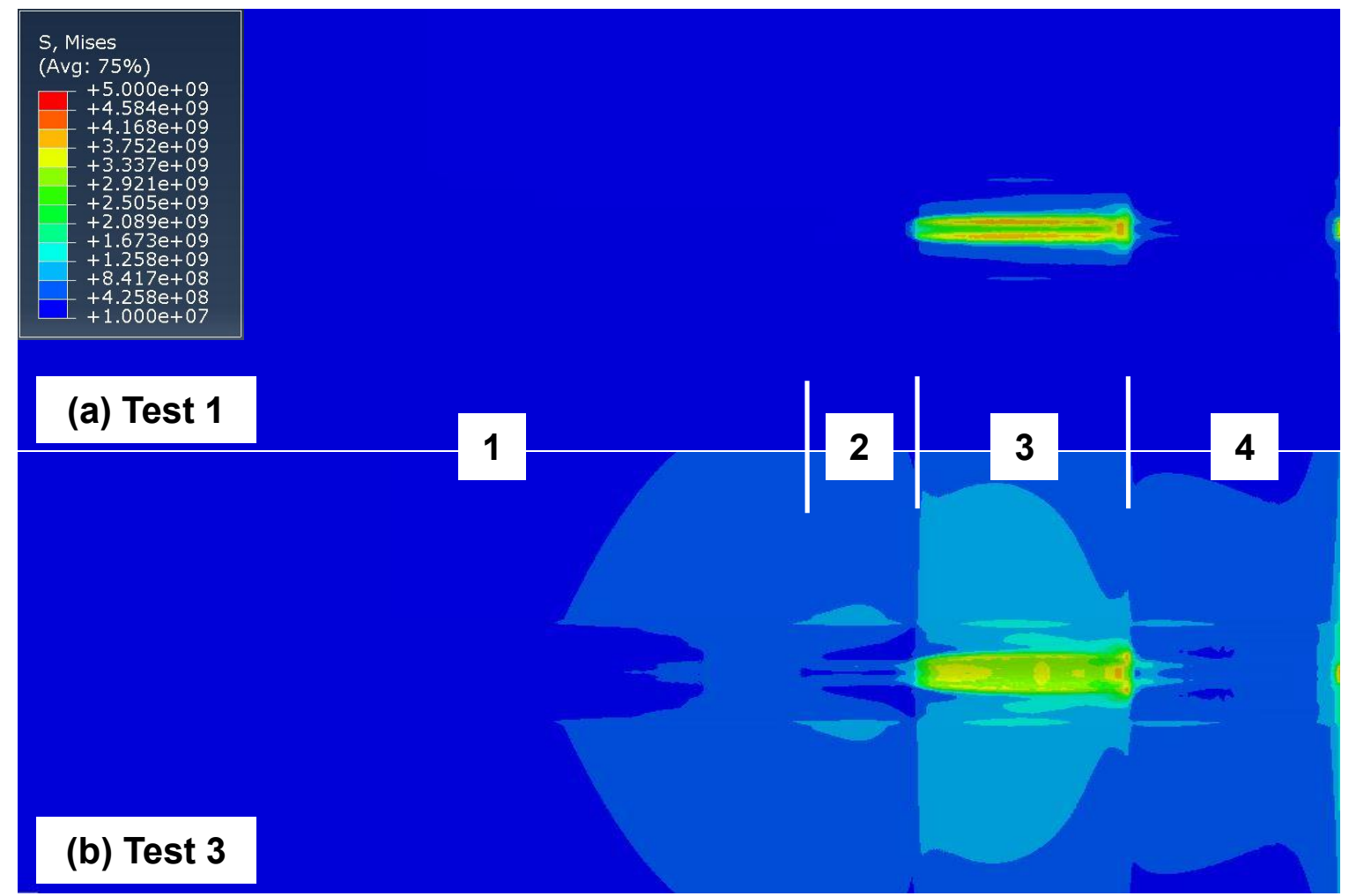

Fig. 7 In-situ stress on the DLC overcoat of the slider (bottom view) of a) test $1\left(V_{x}=25\right.$ $\left.\mathrm{m} / \mathrm{s}, h_{t}=1 \mathrm{~nm}, t=1.5 \mathrm{~nm}\right)$ and b) test $3\left(V_{x}=25 \mathrm{~m} / \mathrm{s}, h_{t}=3 \mathrm{~nm}, t=1.5 \mathrm{~nm}\right)$, where 1 is the AITiC substrate region, 2 and 4 are the $\mathrm{Al}_{2} \mathrm{O}_{3}$ substrate regions, and 3 is the NiFe substrate region. 

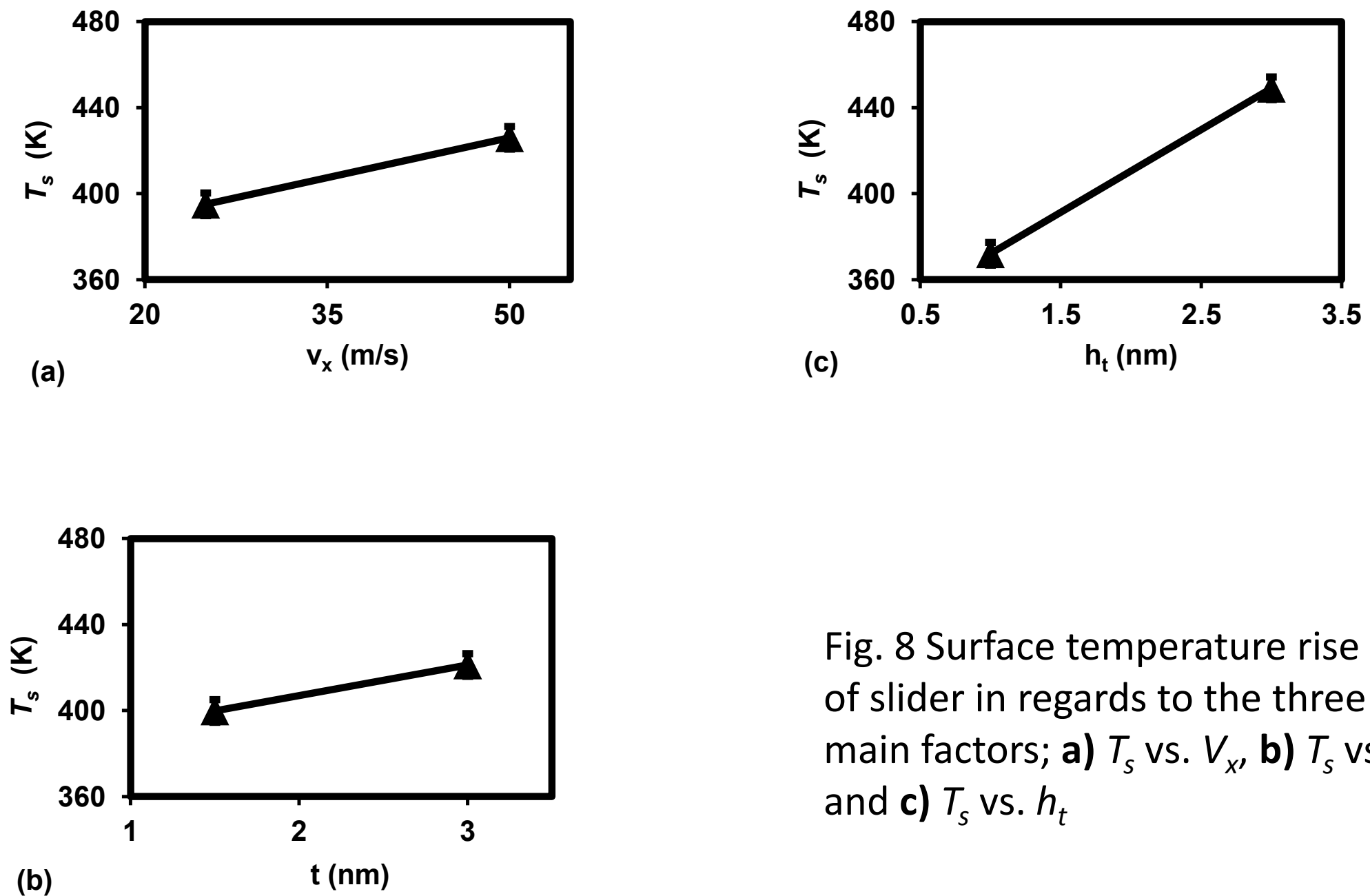

Fig. 8 Surface temperature rise $\left(T_{s}\right)$ of slider in regards to the three main factors; a) $T_{s}$ vs. $V_{x}$, b) $T_{s}$ vs. $t$, and c) $T_{s}$ vs. $h_{t}$

(b)

$\mathrm{t}(\mathrm{nm})$ 